\title{
Investigation of an Acute Fasciolosis Complicated by Clostridia Infection Outbreak in Korem Town, Southern Tigray of Ethiopia
}

\section{Molla Michealay Tesfay ( $\sim$ mmichealay@gmail.com )}

Department of Animal Sciences, Raya University, P.O. Box 42, Maichew, Ethiopia.

\section{Berihun Afera Tadele}

College of Veterinary Sciences, Mekelle University, P.O. Box 2084, Mekelle, Ethiopia

Asmelash Tassew Kebede

Department of Animal Sciences, Raya University, P.O. Box 42, Maichew, Ethiopia.

\section{Yohannes Tekle Asfaw}

College of Veterinary Sciences, Mekelle University, P.O. Box 2084, Mekelle, Ethiopia

\section{Biruk Mekonnen Woldie}

College of Veterinary Sciences, Mekelle University, P.O. Box 2084, Mekelle, Ethiopia

\section{Assefa Kebede Tsegay}

College of Veterinary Sciences, Mekelle University, P.O. Box 2084, Mekelle, Ethiopia

\section{Nigus Abebe Shumuye}

College of Veterinary Sciences, Mekelle University, P.O. Box 2084, Mekelle, Ethiopia

\section{Emebet Adane Dubale}

College of Veterinary Sciences, Mekelle University, P.O. Box 2084, Mekelle, Ethiopia

\section{Hintsa Gebregiorgies Gebreyesus}

Department of Chemistry Raya University, P.O.Box 42, Maichew, Ethiopia

\section{Research Article}

Keywords: acute fascioliasis, Clostridium, Korem, Minchae Bahri, outbreak, sheep

Posted Date: June 18th, 2021

DOI: https://doi.org/10.21203/rs.3.rs-557724/v1

License: (c) (i) This work is licensed under a Creative Commons Attribution 4.0 International License. Read Full License 


\section{Abstract \\ Background}

In December 2018, an outbreak of an unknown disease was reported to affect different animal species largely high number of small ruminant from Tumbio village in Korem town of southern Tigray. This study investigated the clinical characteristics, frequency (place, time, sex, age, physiological states), and primary causal agent(s) of outbreak.

\section{Results}

A total of 1966 cases occurred between 28 November and 21 December 2018, of which 1880 died, making a case fatality rate of $95.6 \%$. The cases presented with inappetance $(n=953)$, thirsty $(n=833)$, pale mucous membrane $(n=676)$, bottle jaw $(n=424)$, swollen tail $(n=398)$, ascites $(n=309)$, suddenly died $(n=324)$, and diarrhea $(n=205)$. The responsible source of exposure was Minchae Bahri (pasture land). Excluding young suckling sheep which did not start grazing all groups of sheep were at risk. Even if, mixed parasitic infections were observed all samples processed parasitological were positive for immature liver flukes. Based on microbiologically finding Clostridium was isolated from 41(82\%) samples. The necropsy and histopathology findings showed that liver is the most injured organ. The immediate interventions were not effective in controlling the outbreak.

\section{Conclusions}

Clinical presentation, immature liver flukes in all processed samples, high level of isolated Clostridium, necropsy and histopathology findings adducts among the cases support the causal role of acute fascioliasis complicated with Clostridium species. Community level awareness, integrated control measure and building diagnostic capacity of district level animal health experts and clinicians is needed.

\section{Background}

In December 2018, an outbreak of an unknown disease was reported to affect different animal species largely high number of small ruminant from Tumbio village in Korem town of southern Tigray. Diseased animals were reported to have symptoms of thirsty, enlarged and distended abdomen, bottle jaw, swollen tail and watery and fetid diarrhea having pungent smell. The disease has caused large number of death mainly sheep. The outbreak was appeared in all sheep grazing on one of the areas called Tumbio (village and kebele 02) of Korem town specifically in Minchae Bahri (pasture land). Minchae Bahri stays marshy for an extended period of the year. This merit the attention of the professionals working in the area as such huge number of loss was not seen previously and the trial that they make in the control of such devastating diseases was not effective. 
As the disease progresses there was request submitted by the southern zone of the region to have expertise to the Bureau of Agriculture and Rural Development to look at possible expertise that can assist them in the outbreak investigation in-order to identify the source of the outbreak and its causes. Through the decimation of livestock outbreaks affect directly or indirectly the health and economic of population [1]. Timely reporting and surveillance of outbreak is mandatory for public health responses. However, no epidemiological surveillance of this unknown disease outbreak was done at this moment. Based on this team a member consisting of epidemiologist, pathologist, microbiologist, infectious disease, parasitologist and toxicologist professionals from Raya and Mekelle University, Ethiopia was assigned in the outbreak investigation. Therefore, having the above background, the objective of our study was to determine the clinical characteristics, frequency (place, time, sex, age, physiological states), and primary causal agent(s) of outbreak.

\section{Results}

\section{Cross-Sectional Observation Distribution of Cases - Place}

The effect outbreak was for those sheep grazed on one of the specific gazing called Menche Bahri (Fig. 1). This area was fenced from June to 30th of august 2018. On the first week of September 2018 the grazing land was opened only for the oxen of Tumbio village of Korem town. Then from November 2018 onward this specific grazing land was opened for all animals of Tumbio village. This grazing land stays marshy for an extended period of the year. Based on the cross-sectional assessment the number of livestock producers involved in Tumbio village was 173 house hold. Average family size of the village was 5 , (range 1 to 12). Before the outbreak average livestock holding of each house hold was 5 cattle, 12 sheep, 5 goat, 1 donkey and 0.3 horses.

\section{Animal Infected During the Cross-Sectional Observation}

At the beginning of the study data were used from all livestock producer of Tumbio village $(n=173)$ and all animal health technicians in Korem town $(n=8)$. All of them declared that the outbreak occurred suddenly only on sheep after they graze over the specific grazing area (Menche Bahri) for about a month. Using the case definition, a total of 800 active cases and 600 died cases were identified to be associated with the outbreak. This makes a case fatality rate of $42.9 \%$. Sheep was entered to Menche Bahri on 1 st of November 2018 for grazing after oxen was grazed for two months. First suspected case was occurred on the 28th of November 2018. Most case then occurred from 1 to 5 December 2018. The epidemic curve showed a common point source epidemic. It showed that animals are exposed over a relatively short period (Fig. 2).

\section{Determine Risk Group}


Among the total 2,086 sheep in the study area, 120 of them was young suckling which did not start grazing. Pregnant and lactating sheep contributed $356(17.07 \%)$ and $250(11.98 \%)$ of the total sheep in the village respectively while as the remaining 1480 (70.95\%) was neither pregnant nor lactating. Sex category of the total sheep was male $(34.7 \%, n=724)$ and female $(65.3 \%, n=1362)$. Attack rate of the outbreak by sex, age and physiological states was calculated and summarized in Table 1 . The result indicates that young suckling sheep which did not start grazing were not at risk for the outbreak while as the outbreak attack rate for sheep that start grazing was 71 cases per 100 individuals at risk. Pregnant and lactating sheep were respectively 1.5 and 1.4 times more likely to be affected by the outbreak than sheep which are neither pregnant nor lactating. Furthermore, females were 1.3 times more likely to be affected by the outbreak than male. Generally the outbreak attack rate was 67 cases per 100 individuals at risk.

Table 1

Attack rate of the outbreak by age, physiological states, and sex group during the cross sectional observation

\begin{tabular}{|lllll|}
\hline Group & & No. of cases & Population & Attack rate (\%) \\
\hline Age & Young suckling & 0 & 120 & 0 \\
\cline { 2 - 5 } & Sheep that start graze & 1400 & 1966 & 71.21 \\
\hline \multirow{2}{*}{$\begin{array}{l}\text { Physiological } \\
\text { states }\end{array}$} & Pregnant & 314 & 356 & 88.20 \\
\cline { 2 - 5 } & Lactating & 202 & 250 & 80.80 \\
\cline { 2 - 5 } & Neither pregnant nor lactating & 884 & 1480 & 59.72 \\
\hline Sex & Male & 410 & 724 & 56.62 \\
\cline { 2 - 5 } & Female & 990 & 1362 & 72.69 \\
\hline
\end{tabular}

\section{Clinical Characteristics}

Diseased animals were reported to have clinical characteristics of inappetance, thirsty, yellowish and pale mucous membranes, bottle jaw, swollen tail, enlarged and distended abdomen (ascites), suddenly died without obvious clinical symptom, and watery and fetid diarrhea having pungent smell. Frequencies of those manifested clinical signs among the total cases are summarized in Table 2. The median incubation period of the outbreak was $32.324(23.14 \%)$ sheep was suddenly died without showing obvious clinical signs which were not receiving veterinary services. $1076(76.86 \%)$ cases were visited veterinary clinic and managed using Oxytetracycline $20 \%$ and Albendazole $600 \mathrm{mg}$ boluses. 
Table 2

Frequency of clinical signs among cases $(n=1400)$

\begin{tabular}{|lll|}
\hline clinical signs & No. of cases & Percentage (\%) \\
\hline Inappetance & 953 & 68.07 \\
\hline Thirsty & 833 & 59.5 \\
\hline Yellowish and pale mucous membrane & 676 & 48.29 \\
\hline Bottle jaw & 424 & 30.29 \\
\hline Swollen tail & 398 & 28.42 \\
\hline Ascites & 309 & 22.07 \\
\hline Suddenly died without obvious clinical signs & 324 & 23.14 \\
\hline Watery and fetid diarrhea having pungent smell & 205 & 14.62 \\
\hline
\end{tabular}

\section{Longitudinal Observation}

\section{Outbreak Prevention and Control Measures}

As the disease outbreak persists the team members in collaborative with Korem veterinary officer started outbreak control measures on the 14st December 2018. The control measures were based on the preliminary survey. Complete restriction of any livestock in the specific grazing land (Menche Bahri) was done. Community level awareness creation was offered for all livestock producer of Tumbio village. All active case and apparently health livestock of the village was treated with Procaine penicillin, triclabendazole and multivitamin. Burial of new death and reburial that had been disposed inappropriately was done. However, treatments were not effective.

\section{Animal Infected During the Longitudinal Observation}

All the total 1486 sheep (800 active case and 686 apparently health) that were grazed in the specific grazing area (Menche Bahri) from all livestock producer of Tumbio village were recruited in the longitudinal observation. Furthermore, all the information recorded during the cross-sectional observation were also considered in this observation and enrolled in these analyses. Using the case definition, a total of 1966 cases were identified to be associated with the outbreak. Among total identified cases, 566 cases were new cases registered after the cores sectional observation from 8 December 2018 to 12 March 2019. But the remaining 1400 cases were those cases identified during the cross-sectional observation. Peak occurrence of cases was occurred during the first week of December 2018 declined over the next two weeks. The last case occurred in 21 December 2018(Fig. 3). Among the total reported cases, 1880 of them were died, making a case fatality rate of $95.6 \%$.

\section{Determine Risk Group}


Once again attack rate of the outbreak by sex, age and physiological states was also calculated during the longitudinal observation and summarized in Table 3. The analyses show that until the end of the study period all (120) young suckling sheep which did not start grazing were not at risk for the outbreak. Whereas the remaining (1966 sheep) with different physiological states and sex was attacked by the outbreak, making attack rate of $100 \%$.

Table 3

Attack rate of the outbreak by age, physiological states, and sex group during the longitudinal observation

\begin{tabular}{|lllll|}
\hline Group & & No. of cases & Population & Attack rate (\%) \\
\hline \multirow{2}{*}{ Age } & Young suckling & 0 & 120 & 0 \\
\cline { 2 - 5 } & Sheep that start graze & 1966 & 1966 & 100 \\
\hline Physiological & Pregnant & 356 & 356 & 100 \\
\cline { 2 - 5 } states & Lactating & 250 & 250 & 100 \\
\cline { 2 - 5 } & Neither pregnant nor lactating & 1360 & 1480 & 91.90 \\
\hline Sex & Male & 682 & 724 & 94.20 \\
\cline { 2 - 5 } & Female & 1284 & 1362 & 94.30 \\
\hline Total & & 1966 & 2086 & 94.25 \\
\hline
\end{tabular}

\section{Laboratory Examination}

\section{Necropsy findings}

In all 50 slaughtered sheep, similar gross pathological changes were observed with enlarged, rounded edges and irregular capsular surface liver. Furthermore, with varying occurrence between those slaughtered sheep; injured gastrointestinal tract with hemorrhage, a bite enlarged mesenteric lymph node and congested and eroded abomasum were another gross pathological changes observed. Additionally, adult Fasciola, cystitis in upper omasum, Homunculus in abomasum, rumen fluke (or paramphistomes) and Trichuris with two and more mixed parasite infection were recovered.

\section{Parasitological Examination}

From the liver of 50 sheep immature fluke recovery was assessed and $50(100 \%)$ of them were identified as positive for immature flukes (Table 4). Furthermore, examination for gastrointestinal helminth infections was performed from faces sample of 50 sheep. Using flotation and sedimentation tests, 50 (100\%) of them were shedding helminth eggs in their faeces. Through their typical characteristics eggs of Strongyles, Fasciola, Paramphistomum, Trichuris, Eimeria and Monezia were identified. Majority of identified eggs were egg of strongyles (54\%) and Paramphistomum (42\%) (Table 4). 
Table 4

Examination for gastrointestinal helminth infections from liver and faces samples

\begin{tabular}{|lll|}
\hline Identified eggs & Total & Sample type (N=50) \\
\hline Immature liver flukes & $50(100 \%)$ & Liver \\
\hline Strongyles & $27(54 \%)$ & Faces \\
Paramphistomum & $21(42 \%)$ & Faces \\
Fasciola & $12(24 \%)$ & Faces \\
Trichuris & $18(36 \%)$ & Faces \\
Monezia & $8(16 \%)$ & Faces \\
\hline
\end{tabular}

\section{Histopathology Findings}

From liver tissues of 50 sheep examination for microscopic lesions were done through histopathologically processes. Accordingly, all the liver (100\%) microscopic sections were found with microscopic lesions such as multifocal necrosis, fibrocystic proliferations in areas where hepatocytes were died and removed, multifocal and diffused infiltrations of inflammatory cells. However, multifocal and diffused infiltrations of inflammatory cells and fibrocystic proliferations were the major and consistent microscopic lesions/findings (Fig. 4).

\section{Bacteriological Investigation}

In this study, liver tissues during post-mortem were collected from 50 sheep and processed for isolation and identification of Clostridium by using staining and cultural. $82 \%(41 / 50)$ of the samples were positive for Clostridium with colony characteristics of small, flat, alpha haemolytic colonies on blood agar and Gram-positive bacilli using gram staining as well the result was sub-terminal endo spores (light green) Vegetative (pink) in spore staining (Figs. 5 and 6).

\section{Discussion}

Outbreaks due to a massive and short term intake of metacercariae are usually the great concern in areas with high rainfall and anything favoring for wetland development combined with a lack of flukes control measures $[13,14]$. Detection of immature flukes in liver sample from 50 sheep out of $50(100 \%)$ and $82 \%$ $(41 / 50)$ Clostridium positive clearly indicates that the outbreak was due to acute fasciolosis predisposed Clostridia infection. This is the first outbreak of an acute fasciolosis predisposed Clostridia infection reported in Ethiopia. However, Fasciolosis with a prevalence of ranging $11.5 \%-87 \%$ is one of the most important parasitic diseases of ruminants in various parts of Ethiopia $[15,16,17,18,19,20]$.

The outbreak occurred on a specific grazing land located in an area endemic for fasciolosis in Tumbio village of Korem town, ofla District [21]. (Topography of the specific grazing land is flat with wetlands. The water is pumped from different drainages of Korem town and stay for almost one month. The 
grazing system of the village for this specific grazing land was by fencing for all most three months the grazing land was opened for oxen only for two months then the grazing land was opened for all livestock population of the village. This provides massive development of metacercaria because of the survival metacercaria before fencing and egg shaded from oxen [22]. Altitude of Korem town is 2539 meters above sea level with temperature ranges of $44^{\circ} \mathrm{F}$ to $78^{\circ} \mathrm{F}$. There was high rainfall from June to the end of August in Korem. All this geographical and environmental characteristics of the area where this outbreak occurred were enhancing the epidemiology of fascioliasis $[23,24,25,26]$.

The clinical features of acute fasciolosis observed in this outbreak were in agreement with previous report $[27,28,14,29]$.

Based on data of cross-sectional and longitudinal observation from Korem veterinarian and livestock producers of Tumbio village of this study, a total of 1966 outbreaks were identified using the case definition. The attack rate and case fatality rate for this outbreak was $94.25 \%$ and $95.6 \%$ respectively, which was much higher than acute fasciolosis reported in various part of the world; attack rate and case fatality of 3 to $66.7 \%$ and 3 to $50 \%$ in southern Brazil [30]; case fatality of $18.3 \%$ on a livestock farm near Minchanabad in Bhawalnagar district [31]; mortality rates range from 15-20\% [32]; $10 \%$ sudden death of flock [13]. The high attack and case fatality rate in acute fasciolosis of this outbreak might be attributed to the fact that geographical and environmental factories provides massive development of metacercaria then the gazing system of the village causes the sheep to consume this massive metacercaria in short period. Additionally, due to absences of clostridial vaccinations practices in the district this acute syndrome was complicated with concurrent Clostridium novyi. Furthermore, this might be due to treatment for fasciolosis in district have been applied randomly and independently in the local herds, without any attempt to adopt an integrated parasite control program for the district including without following any technical recommendation such as correct dosage, frequency, application rout, etc.

Even if, at the end of our results during longitudinal observation indicates that except the young suckling sheep which did not start grazing all sheep group were attacked by the outbreak, the cross-sectional observation showed female, pregnant and lactating sheep were first become ill and died. This could be explained by the fact that, females are more prone to parasitism during pregnancy and peri-parturient period, because this causes stress and decreased immune status [33].

The post-mortem examination was revealed two important points. The first point was the enlarged, rounded edges and irregular capsular surface of liver observed in all 50 slaughtered sheep, which is in agreement with the report of $[34,32]$ study for acute fasciolosis. The second was varying occurrence of multiple gastrointestinal helminthes between slaughtered sheep. Mixed parasitic infections were similarly reported [35, 36].

Parasitological fecal egg and immature fluke examination were done. Based on this parasitological fecal egg examination finding of this study were mixed parasitic infection with predominant helminth egg of Strongyles followed by Paramphistomum. This result was in agreement with previous report in Ethiopia high land sheep [37, 38, 39, 40]. However, no massive deaths were reported in those previous reports. 
Interestingly, in this study immature fluke from live samples were recovered in all (50/50) of the examined samples. This magnifies the presence of immature fluke could potentially contribute for this outbreak. Similarly, immature fluke were recovered in previous acute fasciolosis outbreaks reports even if there were negative for fasciolosis egg $[41,42,34,32]$.

Histopathologically, liver with multifocal necrosis, fibrocystic proliferations in areas where hepatocytes were died and removed, multifocal and diffused infiltrations of inflammatory cells were observed in the present study. This finding is in consistent with other reports of pathological changes caused by acute fasciolosis $[43,30]$.

Out of 50 microbiological examined sheep for Clostridium complication 82\% (41/50) were identified as Clostridium positive. Clostridium was also isolated by $[44,45,46]$ from tissue necrosis and local anaerobiosis of liver caused by migration of immature forms of flukes mainly fasciolosis. Toxemia and profound hypoproteinaemia produced by clostrdial organisms causes liver damage, treatment failure and follows by quickly death (https://www.merckvetmanual.com). Similarly, in this finding no cure was observed after all active case were treated with procaine penicillin, triclabendazole and multivitamin. So it can be concluded that the high case fatality rate and treatment failure of this outbreak caused by acute fasciolosis was due to complication of Clostridium infection.

\section{Conclusions}

The study has indicated that cause for the outbreak was tissue damage by acute fascioliasis complicated with Clostridium species. Excluding young suckling sheep all group sheep were at risk. Specific grazing land called Menche Bahri was the suspected exposure. As compared to previous studies, this outbreak had a high case fatality rate. Fecal egg identification would not potentially useful in diagnosis of acute fascioliasis. Necropsy and histopathology findings showed that liver is the most injured organ. Based on our investigation we recommended the following points: Community level awareness creation on the causes and pathogenesis of the outbreak and their mobilization for effective implementation of the recommended prevention strategies should be done first and the efficient control of fasciolosis should be implemented on the definitive host, intermediate host, and the parasite by integration. Building diagnostic capacity of Wereda level animal health experts and clinicians to enhance their early diagnosis capacity and early warning of such outbreaks is also needed.

\section{Methods}

\section{Study Area}

This study was conducted in Tumbio village of Korem town in which the outbreak was occurred. Korem is a town and located on the eastern edge of Ethiopian highlands in the southern zone of Tigray region. This town has a latitude and longitude of $12^{\circ} 30^{\prime} \mathrm{N} 39^{\circ} 31^{\prime} \mathrm{E}$ coordinates, and an elevation of 2539 meters above sea level. Its temperature ranges from $44^{\circ} \mathrm{F}$ and $78^{\circ} \mathrm{F}$. The area receives mean annual rainfall of 
628.8 millimeter [2]. The predominant production system in Tumbio village is mixed crop-livestock farming and cattle are the most important livestock species reared. According to the report of Department of Agriculture of Korem town, the village has an estimated population of 910 heads of cattle, 2,086 sheep, 840 goats, 180 donkeys, 58 horses and chickens [3].

\section{Epidemiological Survey}

\section{Target population and respondents}

The target population under investigation was case of any livestock residing in Tumbio village, presenting with history of thirsty, enlarged and distended abdomen, bottle jaw, swollen tail and watery and fetid diarrhea having pungent smell from 28 November 2018 onward, or died in that period with the above presentation. While the target respondents were all the 173 household farms in the village as well all the 8 animal health technicians in Korem town.

\section{Study Design}

\section{Cross-sectional study}

After a written consent was obtained a cross-sectional interview questionnaire was administered to the entire producer in the village (Annex I) and animal health technicians in Korem town (Annex II) from December 8-12, 2018. Only cases occurred before December 8-12, 2018 was considered in this crosssectional observation. Collected information was: total animal owned by the producer, number and species of animals faced by the outbreak, suspected exposure, data of first suspected exposure and suspected case occurred, date of most recent case, predominant symptoms, final fate of the infected animal, infection based on physiological states, sex and age, and animal received veterinary services.

\section{Longitudinal study}

After the preliminary cross-sectional was done longitudinal prospective study was followed from 13 December 2018 to 12 March 2019. Cases occurred from December 8-12, 2018 to13 December 2018 were registered in this longitudinal observation. All animals in the village were recruited to the study progressively as they were show case definition presented in target population above. All recruited animals were coded and daily visited. Individual animal information was also collected in this study design as planned above in cross-sectional study. Furthermore, by randomly selection from those recruited animals in the study 50 sheep were sampled for laboratory investigation as well postmortem were done on all of those 50 selected sheep (active case).

\section{Laboratory investigations}

\section{Parasitological Examination}

Form each of those randomly selected 50 active case sheep cut sections of livers and faeces samples were analyzed respectively for immature fluke recovery and parasitic egg identification. After collection all 
the specimens were kept in ice-box and carried to College of Veterinary Sciences, Mekelle University, Ethiopia parasitology laboratory and stored in refrigerator $\left(4^{\circ} \mathrm{C}\right)$ until processing. Faecal samples were collected from rectum and put into standard universal bottles and labeled. The samples were processed by using standard flotation and sedimentation techniques as stated by Urquhart [4] and Foreyt [5]. Cut sections of livers samples were thoroughly washed with cold water and the washings examined microscopically for flukes as per procedures described by Hansen and Perry [6].

\section{Bacteriological Investigation}

Based on clinical symptoms and history bacteriological investigation was undertaken to isolate and identify Clostridium organisms from those selected for parasitological examination. Liver tissue specimens were targeted for laboratory analysis. The specimens were collected aseptically from each animal, transferred into an ice-box and carried to the microbiology laboratory of the College of Veterinary Science, Mekelle University, Ethiopia. Isolation and identification of Clostridium organisms from liver tissue were performed as per procedures described by [7, 8]. Necrotic liver tissue sampled and excised aseptically, placed in two sterile glasses each with fastidious broth (tryptose) and homogenized by vortex mixing. One tube of the homogenized tissue/broth suspension was treated with heat set at $80^{\circ} \mathrm{C}$ for 10 min; the other tube left non-heat-treated suspensions. Both tissue suspensions were primarily cultured in nutrient broth then sub-cultured in the blood agar anaerobically at $37^{\circ} \mathrm{C}$ for 24 to $48 \mathrm{hrs}$. The colonies from the liver tissue were stained using Gram's staining. Similarly, the presumptive colonies of Clostridium in blood agar media were characterized microscopically by using Gram's staining [9]. Furthermore, the suspected colonies of Clostridium were also stained by special staining methods, spore stain [10].

\section{Histopathology Techniques}

For pathological examination tissue samples from liver were collected and stored in sterile manner at College of Veterinary Science, Mekelle University, Ethiopia pathology laboratory until they were tested by histopathology. Tissues samples were trimmed and put in the plastic tissue cassettes and then processed using an automatic tissue processer. Specimen processing were performed as per procedures described by Nayak [11] orderly in automatic tissue processer.

\section{Postmortem Examination}

Following the clinical and physical examination, detailed postmortem examination was done, photographs were captured. Main diagnoses were done using the method developed by McConnell [12].

\section{Data Management and Analysis}

Data were analyzed Using SPSS statistical software version 20. Maps were used to display geographical information. For the different variables descriptive statistic such as count, percentage and frequency was used and presented as tables and figures. For confirmation the existence of epidemic the time course was 
analyzed using histogram. Incubation period was presented using median. Attack rate were calculated based of physiological states, age and sex.

\section{Abbreviations}

Not applicable

\section{Declarations}

\section{Ethics approval and consent to participate}

The study reviewed by Animal Ethics and Experimentation review process of the Research and Community Services Council Office of the Raya University, Ethiopia(R/P/D/12/2018). Samples collected after getting verbal consent from willing owners.

\section{Consent for publication}

Not applicable.

\section{Availability of data and materials}

The datasets used and/or analyzed during the current study are available from the corresponding author on reasonable request.

\section{Competing interests}

The authors declare that they have no competing interests.

\section{Funding}

The study received financial support from Raya and Mekelle University medium scale project award to Molla Michealay and his team. The funder(s) had no role in the design of the study, collection, analysis, and interpretation of data, and in writing the manuscript.

\section{Authors' contributions}

Molla Michealay, Berihun Afera, Yohannes Tekle and Biruk Mekonnen, have conceived study, collected samples and processed in laboratory. Asmelash Tassew, Assefa Kebede, Nigus Abebe, and Emebet Adane 
have collected data and collected samples. Hintsa Gebregiorgies Gebreyesus analyzed data and wrote the draft manuscript. All have read and approved the final manuscript.

\section{Acknowledgments}

I am very grateful to Raya and Mekelle University for funded as to accomplish the project. I also extend my sincere thanks to Mekelle University staff members of the laboratory course teams of veterinary microbiology, pathology and parasitology, who contributed a lot for processing the sample and collecting data in laboratory. My special thanks go to the district experts, animal health coordinator for their unreserved help in program coordination and data collection at field. I am also grateful for those all livestock producer of the village for their kindly participating in the research.

\section{Author details}

${ }^{1}$ Department of Animal Sciences, Raya University, P.O. Box 42, Maichew, Ethiopia. ${ }^{2}$ College of Veterinary Sciences, Mekelle University, P.O. Box 2084, Mekelle, Ethiopia.

\section{References}

1. Yoon H, Jeong W, Han JH, Choi J, Kang YM, Kim YS, Park HS, Carpenter TE. Financial Impact of Footand-mouth disease outbreaks on pig farms in the Republic of Korea, 2014/2015. Preventive veterinary medicine. 2018 Jan 1; 149:140-2.

2. DOA (Department of Agriculture). Annual progress reports. Ofla woreda, southern Tigray of Ethiopia. 2018.

3. DOA (Department of Agriculture). Annual progress reports. Ofla woreda, southern Tigray of Ethiopia. 2017.

4. Urquhart, G.M., J. Armour, J.L. Duncan, A.M. Dunn and F.W. Jennings. Veterinary Parasitology 2nd ed. In: the laboratory diagnosis of parasitism. Blackwell science, United Kingdom. 1985; 276-277.

5. Foreyt, W. J. Veterinary Parasitology Reference Manual. Ames, lowa. 2001; 45-222.

6. Hansen and Perry. The epidemiology, diagnosis and control of helminth parasites of ruminants. 1994; Pp.56.

7. OIE (Office International Des Epizooties). Mannual of standards for diagnostics test and vaccines. 2000; OIE Guide-2.

8. Brazier JS, Duerden BI, Hall V, Salmon JE, Hood J, Brett MM, McLauchlin J, George RC. Isolation and identification of Clostridium spp. from infections associated with the injection of drugs: experiences of a microbiological investigation team. Journal of medical microbiology. 2002 Nov 1;51(11):985-9.

9. Merchant IA, Packer RA. Veterinary bacteriology and virology. 1967. 
10. Quinn PJ, Markey BK, Carter ME, Donnelly WJ, Leonard FC. Veterinary microbiology and microbial disease. Blackwell science; 2002.

11. Nayak R. Histopathology techniques and its management. JP Medical Ltd; 2017 Dec 31.

12. McConnel CS, Garry FB, Hill AE, Lombard JE, Gould DH. Conceptual modeling of postmortem evaluation findings to describe dairy cow deaths. Journal of dairy science. 2010 Jan 1;93(1):373-86.

13. Holmes E, Elkins P. Treatment and management of acute liver fluke cases. Veterinary Times. 2016 Jul 25;46(29):6-8.

14. Radostits OM, Gay CC, Hinchcliff KW, Constable PD. A textbook of the diseases of cattle, horses, sheep, pigs and goats. Veterinary medicine. 2007;10:2045-50.

15. Tsegaye T. Epidemology of bovine fasciolosis and hydatidosis in debre brehan region. DVM thesis, FVM, debre zeit, Ethiopia. 1995:56.

16. Zewdu B. Prevalence and economic analysis of liver fluke infestation in cattle slaughtered at Jimma Municipal Abattoir. Addis Ababa University, Faculty of Veterinary Medicine, Debre Zeit, Ethiopia, DVM Thesis. 1991.

17. Dagne M. Survey on prevalence and economic significance of bovine fasciolosis in Debre Berhan region. DVM Thesis, Faculty of Veterinary Medicine, Addis Ababa University, Debre Zeit, Ethiopia. 1994.

18. Solomon W, Abebe W. Effects of a Strategic Anthelmintic Treatment Intervention for Bovine Fasciolosis: A Study Conducted in Facilities Endemic Area in North Western Ethiopia. Ethiopia Veterinary Journal. 2007; 11: 59-68.

19. Girmay T, Teshome Z, Hailemikael A. Prevalence and Economic Losses of bovine fasciolosis at Hawzien Abattoir, Tigray Region Northern Ethiopia. J. Vet. Adv. 2015;5(5):949-51.

20. Alemu B. Bovine Fasciolosis in Ethiopia-A review. J Vet Ani Res. 2019;2:202.

21. Legesse G, Asfaw Y, Tolossa YH, Beyene TJ. Epidemiology and economic importance of fasciolosis of domestic ruminants in selected districts of Tigray Region, Ethiopia. Ethiopian Veterinary Journal. 2014;18(2):51-64.

22. Njau BC, Scholtens RG. The role of traditionally harvested hay in the transmission of ovine fasciolosis in the Ethiopian highlands. Veterinary research communications. 1991 Sep 1;15(5):369 72.

23. Mulugeta T. Prevalence and Economic Significance of Bovine Fasciolosis at the SopralKombolcha meat factory. DVM thesis, Faculty of Veterinary Medicine, Addis Ababa University, DebreZeit, Ethiopia. 1993.

24. Yilma JM, Malone JB. A geographic information system forecast model for strategic control of fasciolosis in Ethiopia. Veterinary parasitology. $1998 \mathrm{Jul}$ 31;78(2):103-27.

25. World Health Organization. Report of the WHO informal meeting on use of triclabendazole in fascioliasis control: WHO headquarters, Geneva, Switzerland 17-18 October 2006. World Health Organization; 2007. 
26. Wokem Gloria N. Epizootiology of Fascioliasis and its Public Health Implications in Some Communities Near University Of Port Harcourt, Rivers State, Nigeria. Current Trends in Biomedical Engineering \& Biosciences. 2017;9(4):81-6.

27. Urquhart GM, Armour J, Duncan JL, Dunn AM, Jennings FW. Veterinary Parasitology 2nd Edition. University of Oxford.1996.

28. Mason CS. Fasciolosis associated with metabolic disease in a dairy herd and its effects on health and productivity. Cattle practice. 2004 Feb 1;12:7-13.

29. Hashemnia M, Rezaei F, Nikousefat Z, Ghashghaii A. Acute caprine fasciolosis: a case with unusual migration to lung. Journal of parasitic diseases. 2015 Sep;39(3):514-7.

30. Fiss L, de Lourdes Adrien M, Marcolongo-Pereira C, Assis-Brasil ND, Sallis ES, Riet-Correa F, Ruas JL, Schild AL. Subacute and acute fasciolosis in sheep in southern Brazil. Parasitology research. 2013 Feb;112(2):883-7.

31. Afzal M, Qasim Khan M, Hussain M. An outbreak of acute fasciolosis in goats. PAKISTAN VETERINARY JOURNAL. 1997;17:154-5.

32. Adrien, M.D.L., Schild, A.L., Marcolongo-Pereira, C., Fiss, L., Ruas, J.L., Grecco, F.B. and Raffi, M.B., 2013. Acute fasciolosis in cattle in southern Brazil. Pesquisa Veterinária Brasileira. 2013; 33(6):705709.

33. Khan MN, Sajid MS, Khan MK, Iqbal Z, Hussain A. Gastrointestinal helminthiasis: prevalence and associated determinants in domestic ruminants of district Toba Tek Singh, Punjab, Pakistan. Parasitology research. 2010 Sep;107(4):787-94.

34. Scott PR, Sargison ND, Macrae A, Rhind SR. An outbreak of subacute fasciolosis in Soay sheep: ultrasonographic biochemical and histological studies. The Veterinary Journal. 2005 Nov 1;170(3):325 - 31 .

35. Bersissa K, Tigist T, Teshale S, Reta D, Bedru H. Helminths of sheep and goats in central Oromia (Ethiopia) during the dry season. Journal of Animal and Veterinary advances. 2011;10(14):1845-9.

36. Wang CR, Qiu JH, Zhu XQ, Han XH, Ni HB, Zhao JP, Zhou QM, Zhang HW, Lun ZR. Survey of helminths in adult sheep in Heilongjiang Province, People's Republic of China. Veterinary Parasitology. 2006 Sep 10;140(3-4):378-82.

37. Bekele T, Woldeab T, Lahlou-Kassi A, Sherington J. Factors affecting morbidity and mortality on-farm and on-station in the Ethiopian highland sheep. Acta Tropica. 1992 Dec 1;52(2-3):99-109.

38. Legesse G. Livestock health situation in central Tigray: rural exploratory studies in the central zone of Tigray, Northern Ethiopia. Proceeding of a work shop, Oyhus, AO and Gebru, G. Agricultural University of Norwegian (AUN). 1996:83-100.

39. Belay B. Traditional sheep management and production situation in the south western Part of Ethiopia.1998.

40. Abraha GG. Major animal health problems of market oriented livestock development in Atsbi Womberta woreda, Tigray regional state (Doctoral dissertation, Addis Ababa University).2007. 
41. Boray JC. Studies on experimental infections with Fasciola hepatica, with particular reference to acute fascioliasis in sheep. Annals of Tropical Medicine \& Parasitology. 1967 Dec 1;61(4):439 - 50.

42. Brunsdon RV. Liver fluke Fasciola hepatic a in sheep and cattle in New Zealand and its control. New Zealand veterinary journal. 1967 Jan 1;15(1-2):9-23.

43. Martınez-Moreno A, Jiménez-Luque V, Moreno T, Redondo ES, de las Mulas JM, Pérez J. Liver pathology and immune response in experimental Fasciola hepatica infections of goats. Veterinary parasitology. 1999 Mar 22;82(1):19-33.

44. Smith BP. Large animal internal medicine-E-Book. Elsevier Health Sciences; 2014 Apr 21.

45. Bagadi HO, Sewell MM. Experimental studies on infectious necrotic hepatitis (Black Disease) of sheep. Research in veterinary science. 1973 Jul 1;15(1):53-61.

46. Stalker, M.J., Hayes, M.A.T. and Maxie, M. Jubb, Kennedy and Palmer's Pathology of Domestic Animals. Liver and biliary system. 2007; 298-358.

\section{Figures}

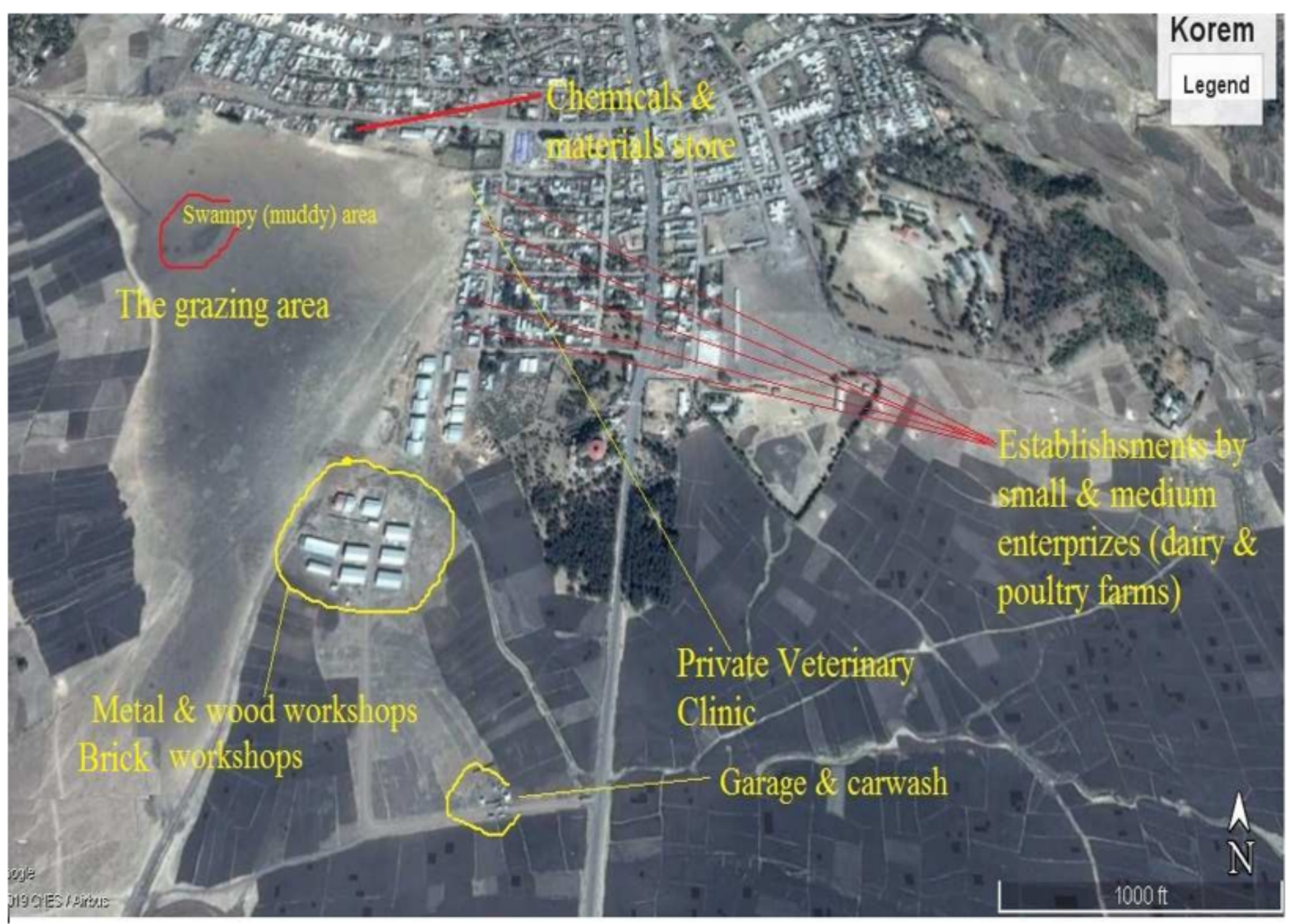


Study area map. Map produced by the authors. The maps were produced using QGIS software applications version 3.12.3 Note: The designations employed and the presentation of the material on this map do not imply the expression of any opinion whatsoever on the part of Research Square concerning the legal status of any country, territory, city or area or of its authorities, or concerning the delimitation of its frontiers or boundaries. This map has been provided by the authors.

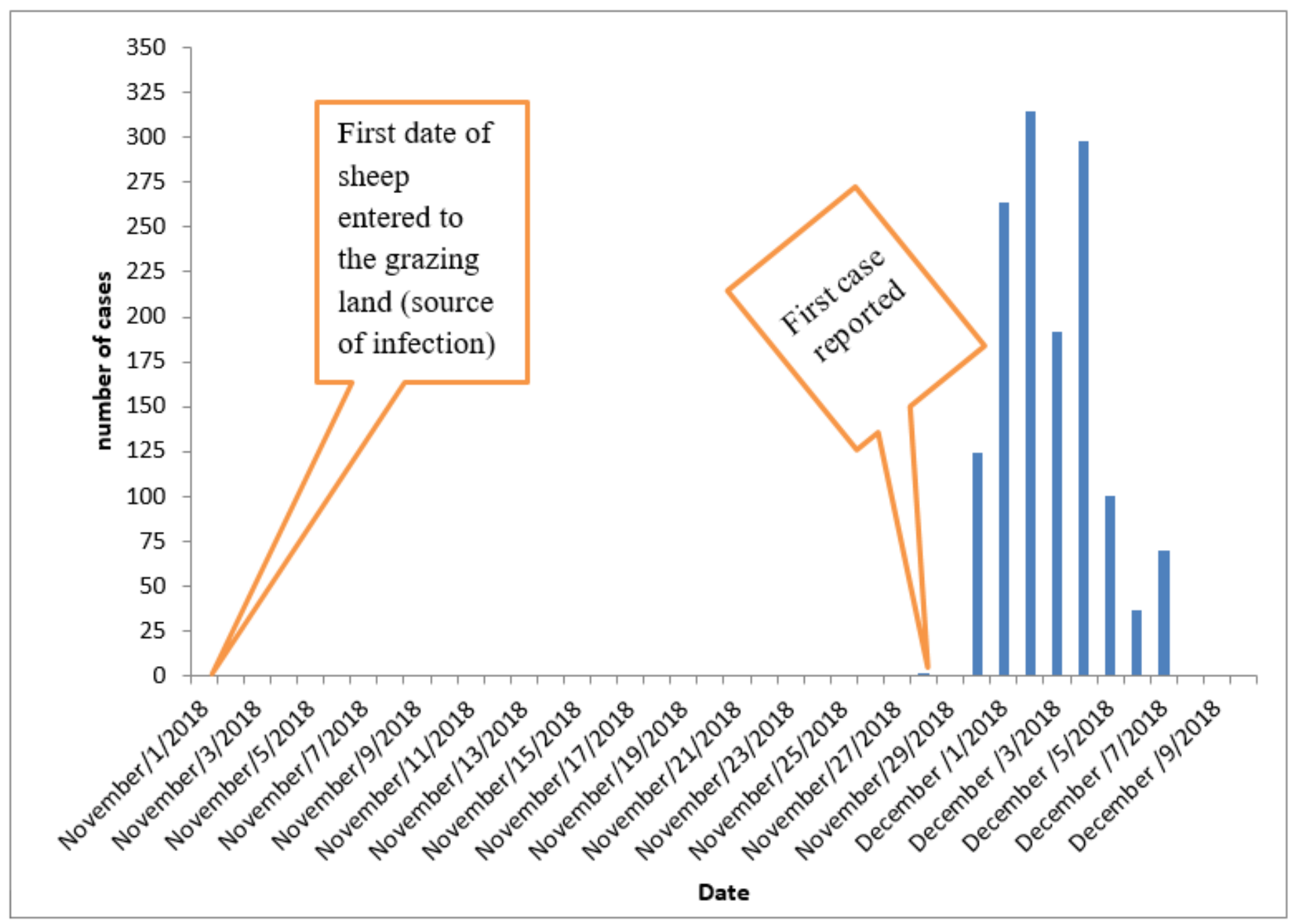

Figure 2

Epidemiological curve of the outbreak in Tumbio village of Korem town during the cross sectional observation in 2018 


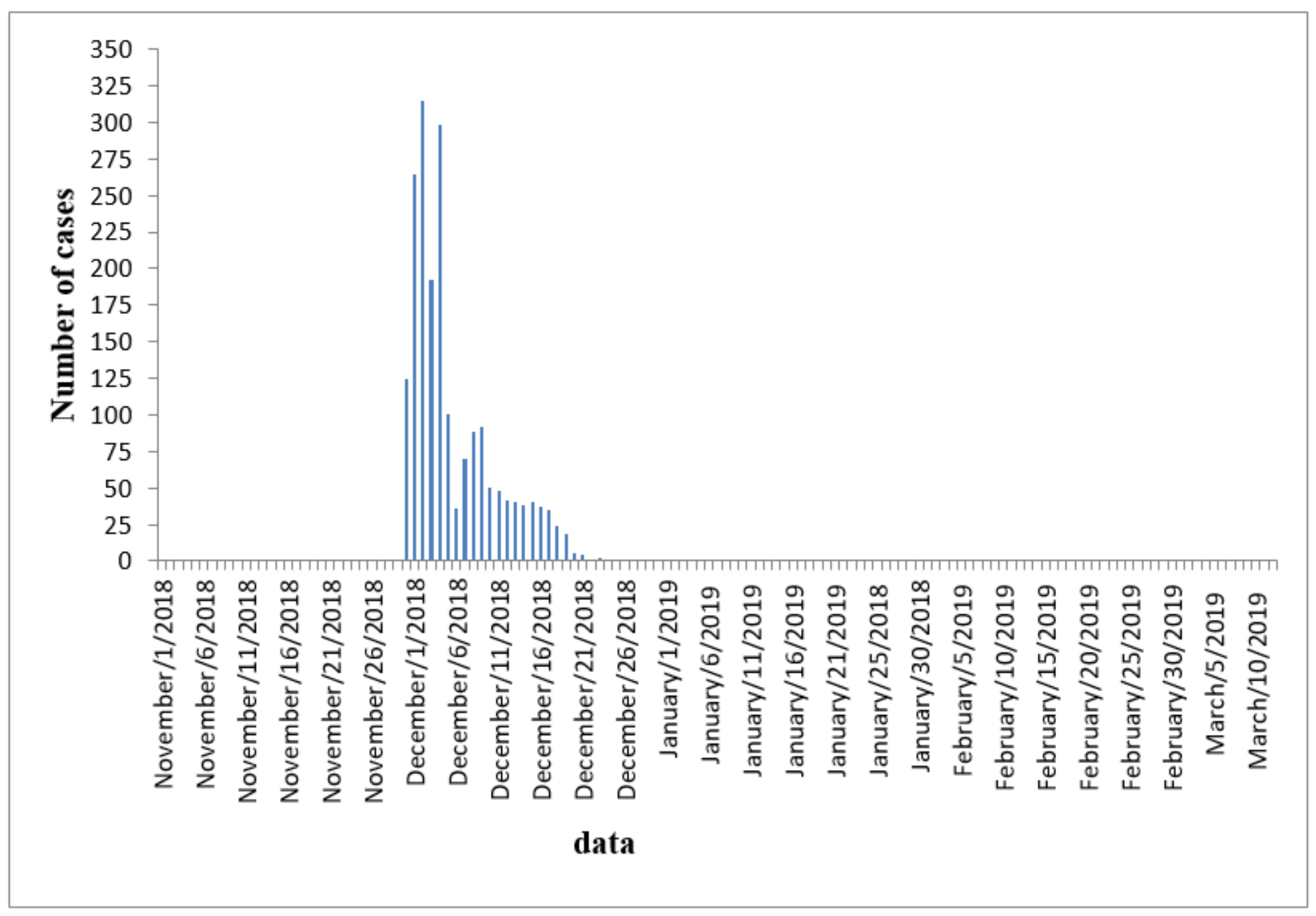

Figure 3

Epidemiological curve of the outbreak in Tumbio village of Korem town during the longitudinal observation 


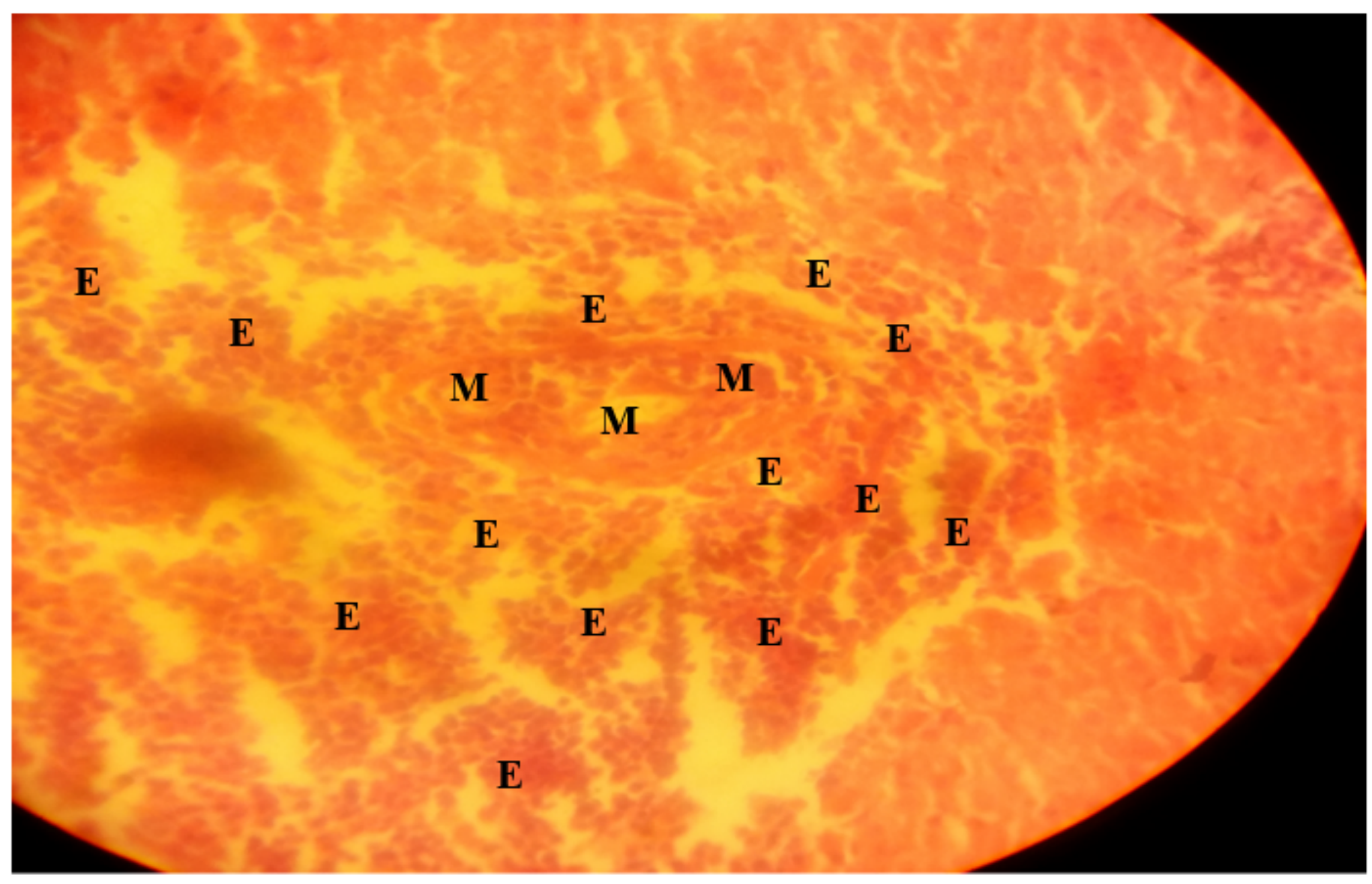

\section{Figure 4}

Focal and diffused infiltrations of inflammatory cells (Eosinophils) around a cross sections of metacercaria (an infective stage of fasciola parasites), HE, 100x.

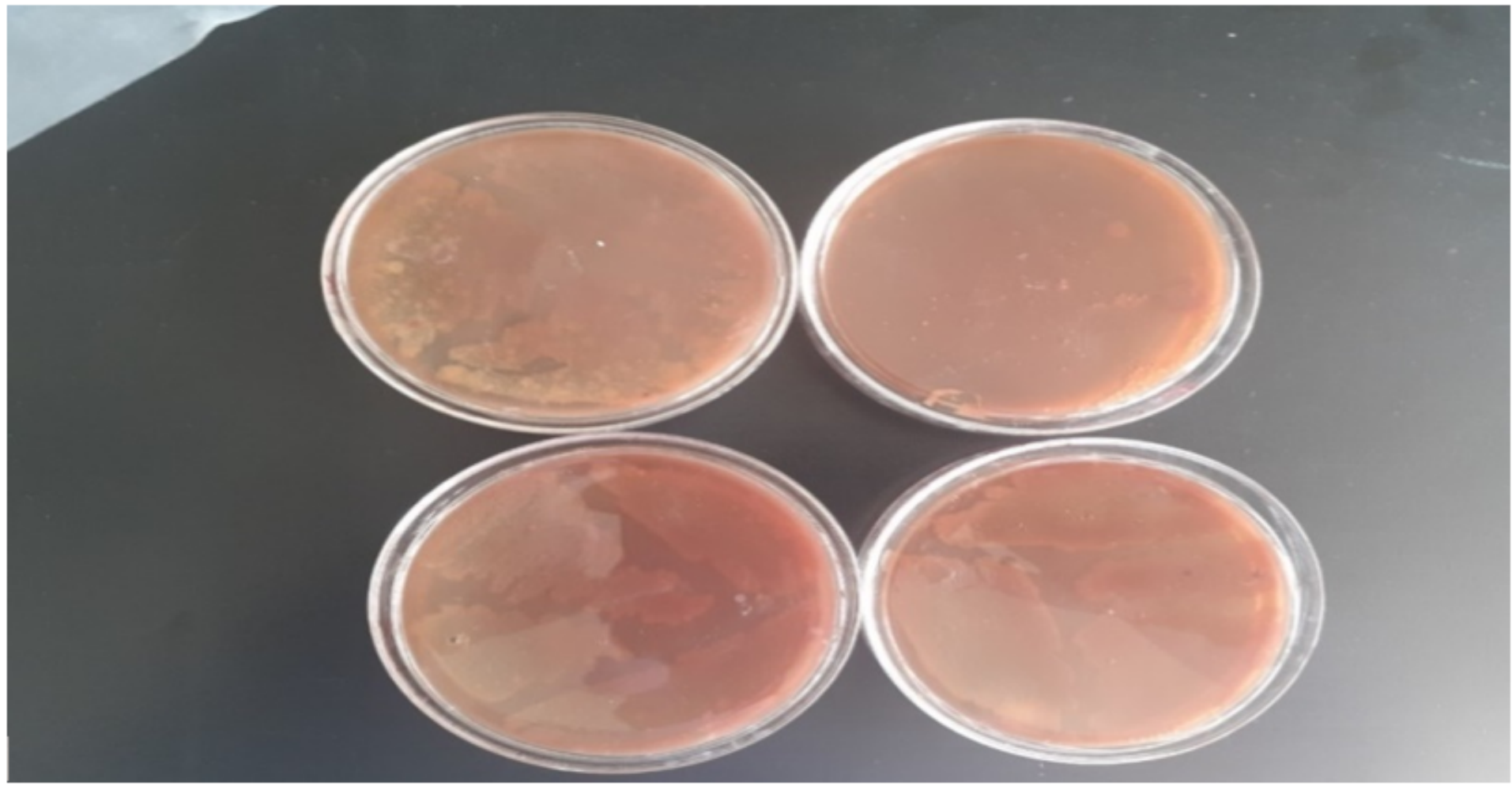


Figure 5

Small, Flat, alpha-hemolytic Colonies on Blood Agar

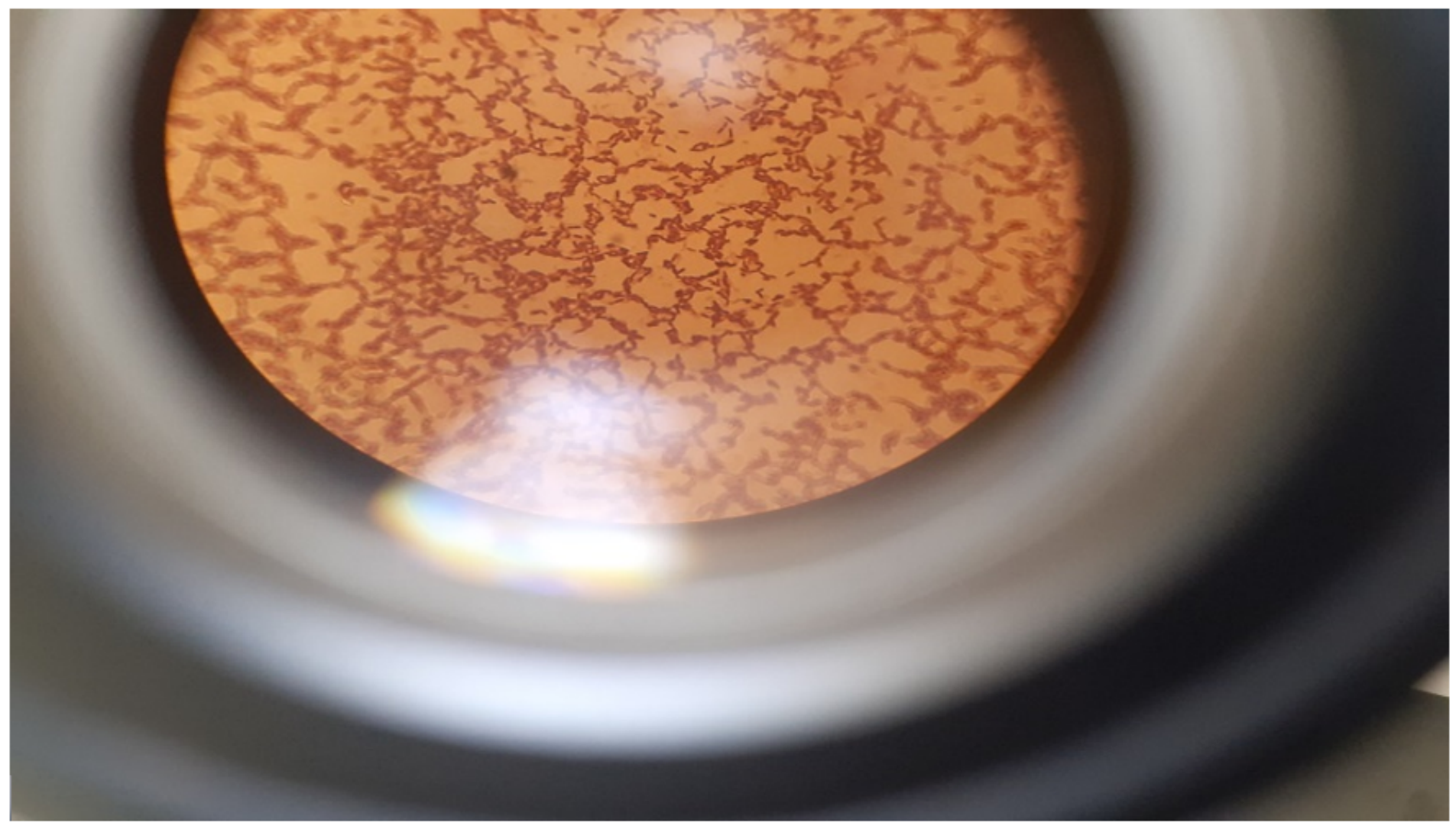

Figure 6

Gram-positive large bacilli/rods

\section{Supplementary Files}

This is a list of supplementary files associated with this preprint. Click to download.

- Questionnaireforanimalhealthtechnicians.docx

- Questionnaireforanimalowners.docx 